\title{
Why some employees might thrive on job insecurity: Human values as a moderating factor in the job insecurity - wellbeing relationship
}

\author{
Ola Sjöberg
}

\begin{abstract}
The purpose of this study is to analyse the extent to which human values moderate the impact of job insecurity on life satisfaction and subjective wellbeing. Drawing upon conservation of resources theory, we argue that human values may affect both the relative importance of resources as well as the competency to successfully adjust to a changing work context. This theoretical framework leads to the expectation that individuals who are motivated by values emphasising variety seeking and taking on challenges in life will suffer less from job insecurity, whereas the wellbeing and life satisfaction of individuals with values motivating them to avoid uncertainty and resist change will be affected relatively more by job insecurity. Empirical analyses, using data from 28 countries from two waves of the European Social Survey, are largely supportive of these hypotheses.
\end{abstract}

Keywords: wellbeing, human values, job insecurity

\section{Introduction}

Job insecurity has been described as the disease of the 21st century. It has been argued that increasingly competitive world markets, automation, and recurring recessions mean that citizens of high-income countries, who used to live in a "20-year career and a gold watch" model, now live in a culture of perpetual job insecurity which acts as a powerful and chronic stressor in their lives (Scott, 2004). A large body of research has documented that higher levels of subjective job insecurity are associated with lower psychological wellbeing and life satisfaction (for overviews, see De Witte, 2005; De Witte, Pienaar \& De Cuyper, 2016; Ferrie, Westerlund, Virtanen, Vahtera, \& Kivimäki, 2008; Griep et al., 2016). Research has, in fact, shown that experiencing job insecurity can be as distressing as experiencing actual unemployment (De Witte, 1999).

There is, however, still limited knowledge about the mechanisms translating job insecurity into reduced wellbeing and life satisfaction. A central question in this context is why some people seem to be more or less unaffected by job insecurity, whereas it acts as a powerful stressor for other employees with similar "objective" characteristics in terms of, for example, education and tenure. A number of studies have therefore tried to identify factors that moderate the relationship between job insecurity and psychological wellbeing. Employability (i.e., alternatives in the labour market) has been proposed as one such factor (Silla, De Cuyper, Gracia, Peiró, \& De Witte, 2009), psychological resources such as self-esteem and optimism (Mäkikangas \& Kinnunen, 2003), and perceived control (Ito \& Brotheridge, 2007) as others. The identification of such moderating factors is crucial for our theoretical understanding of job 
insecurity, and ultimately also for the ability of organisations and society to deal adequately with it.

In this study, it is proposed that human values are an important moderator in the relationship between subjective job insecurity and subjective wellbeing and life satisfaction. Human values are deeply rooted abstract motivations that guide and justify attitudes, opinions, and actions (Schwartz, 2006a). Drawing upon Hobfoll's (1989) Conservation of Resources (COR) theory, which maintains that perceived threats to valued resources may lower people's wellbeing, we argue that human values may affect both the relative importance of resources ("resource-importance appraisal") as well as the competency to successfully adjust to a changing work context ("cognitive flexibility" and "adaptive orientation"). This theoretical framework leads to the expectation that individuals who are motivated by values emphasising variety seeking and taking on challenges in life will suffer less from job insecurity, whereas the wellbeing and life satisfaction of individuals having values motivating them to avoid uncertainty and to resist change will be affected relatively more by job insecurity. Propositions derived from this theoretical framework are tested on data from 19 countries from the European Social Survey.

\section{Job insecurity, conservation of resources and human values}

The central assumption in the COR theory is that individuals "strive to obtain, retain, protect, and foster those things that they value" (Hobfoll, 2001, p. 341). ${ }^{1}$ What people value - resources - are objects, personal characteristics, conditions or energies that are either valued in their own right, or are valued because they act as conduits to the achievement or protection of other valued resources (Hobfoll, 2001, p. 339). Psychological stress, possibly resulting in reduced wellbeing, will, according to the COR theory, occur in three instances: (i) when resources are under the threat of being lost, (ii) when individuals' resources are actually lost, or (iii) where individuals fail to gain sufficient resources following significant resource investment (Hobfoll, 1989).

Job insecurity means that valued resources are under the threat of being lost. These valued resources include both manifest (a salary) and latent (e.g., social networks, self-esteem, status, societal recognition, and a sense of contributing to a higher collective purpose) functions of work (Jahoda, 1982). Thus, if a person feels that the valued resources associated with having a job are threatened, he or she is likely to experience psychological strain and reduced wellbeing. When faced with the risk of losing valued resources, individuals may use different coping strategies (Hobfoll, 1989, 2001). Substitution is one such strategy, where resources that are under threat of being lost are substituted. People who face job insecurity may invest more in their out-of-work social networks to substitute for the potential loss of social support from work colleagues. Another possible strategy is to strive to minimise the net loss of resources. Facing job insecurity, people might try to minimise effort investment in work tasks and switch to activities that are less resource demanding. Alternatively, people may try to defend existing resources by working harder in an attempt to influence firing decisions by management.

Of particular importance in this context is what Hobfoll (1989, p. 519) termed reinterpretation as a strategy for coping with job insecurity. By reinterpreting threats as challenges, individuals shift the focus of attention to what might be gained instead of what

\footnotetext{
${ }^{1}$ For other studies using the COR theory for analysing job insecurity, see e.g., De Cuyper, Mäkikangas, Kinnunen, Mauno \& De Witte, 2012; König, Debus, Häusler, Lendenmann \& Kleinmann, 2010; Mauno, Kinnunen \& Ruokolainen 2007.
} 
might be lost in a particular situation. In the original formulation of the COR theory, hardiness was given as an example of a psychological resource that is beneficial for such individual adaptability. Kobasa, Maddi and Courington (1981, p. 369) define hardiness as being composed of three elements: commitment - hardy persons are curious about life and view it as essentially meaningful, control - hardy persons tend to believe that they have the ability to influence the course of events, and challenge - hardy persons tend to believe that it is normal for life to change, and regard this as an important stimulus to development.

Focusing on individual psychological resources that may contribute to individual adaptability - the competence to successfully adjust to a changing work context - Van Dam (2013) has made a useful distinction between the two related aspects "cognitive flexibility" and "adaptive orientation." "Cognitive flexibility" refers to mental abilities relevant for adaptive responses, and especially the ability to consider new ideas and solutions and to alter the perception of situations (Good, 2014). Examples of such "mental abilities" are openness, novelty seeking, and creativity. Such abilities are closely related to the notion of "reinterpretation" as a way of coping with the threat of resource loss. "Adaptive orientation" is related to attitudes and beliefs concerning change, and entails attitudes and beliefs relevant for dealing with new or changing situations.

Over recent decades, a number of psychological resources - often referred to as psychological resilience (Fletcher \& Sarkar, 2013) - have been proposed as contributing to positive adaptability when facing stressful events and for understanding why some people become overwhelmed by even minor adverse experiences, whereas others react positively to stressful events. Examples of such psychological resources are self-efficacy and optimism. Richardson (2002) has described resilience research as comprising three waves, in which resilience as a personal trait is the first wave, resilience as a process - how individuals acquire resilient qualities - is the second wave, and the third wave is research on resilience as identification of motivational forces within individuals or groups that enable them to grow through adversity.

We propose that human values may be one fruitful way of thinking about such motivational forces. In this study, we use the conceptualisation of, and measurement approach to, human values developed by Schwartz (2006a, 2006b, 2015). Schwartz argues that the following common understanding of how to conceptualise human values has emerged in the last decades: firstly, values are linked to affect - when values that are central to us are threatened, we are filled with emotions. Secondly, values refer to desirable goals that motivate action. Thirdly, values serve as standards or criteria against which actions and events are evaluated. Fourthly, values can be ranked according to their importance for individuals or groups, so that there exists a relatively stable system of value priorities. In real life situations, it is the relative importance of and trade-off among relevant values that guide attitudes, actions, and behaviours. Lastly, values, unlike attitudes, transcend specific situations.

Schwartz has proposed that there are 10 motivationally distinct types of values that are recognised by the members of most societies. These values can be arranged in a circular structure that illustrates the conflicts and compatibilities between them (Figure 1 below). Values are dynamically related to each other, which implies that if one value is positively related to an attitude or behaviour, its adjacent values should also relate positively to that attitude or behaviour, while the opposing values in the circle should relate less positively or even negatively to the same attitude or behaviour.

Of special interest in this study are the value dimensions "stimulation" and "security." Individuals who are motivated by values included in the value dimension "stimulation" are 
motivated by a desire to take on challenges in life, by seeking variety, creativity, and intellectual curiosity. These motivational forces are very similar to the concepts of "cognitive flexibility" and "adaptive orientation" discussed earlier. In contrast, individuals who are motivated by "security" values are motivated to avoid uncertainty by controlling relationships and resources and by resisting change. The pursuit of "security" values is likely to come into conflict with the pursuit of "stimulation" values: seeking stability of society, of relationships, and of self is likely to inhibit seeking novelty, challenge, and excitement. There is a strong correlation between age and "security" values, presumably because people become more committed to habitual patterns and more embedded in social networks as they grow older (Schwartz et al., 2012).

Figure 1. Human values (Schwartz, p. 425)

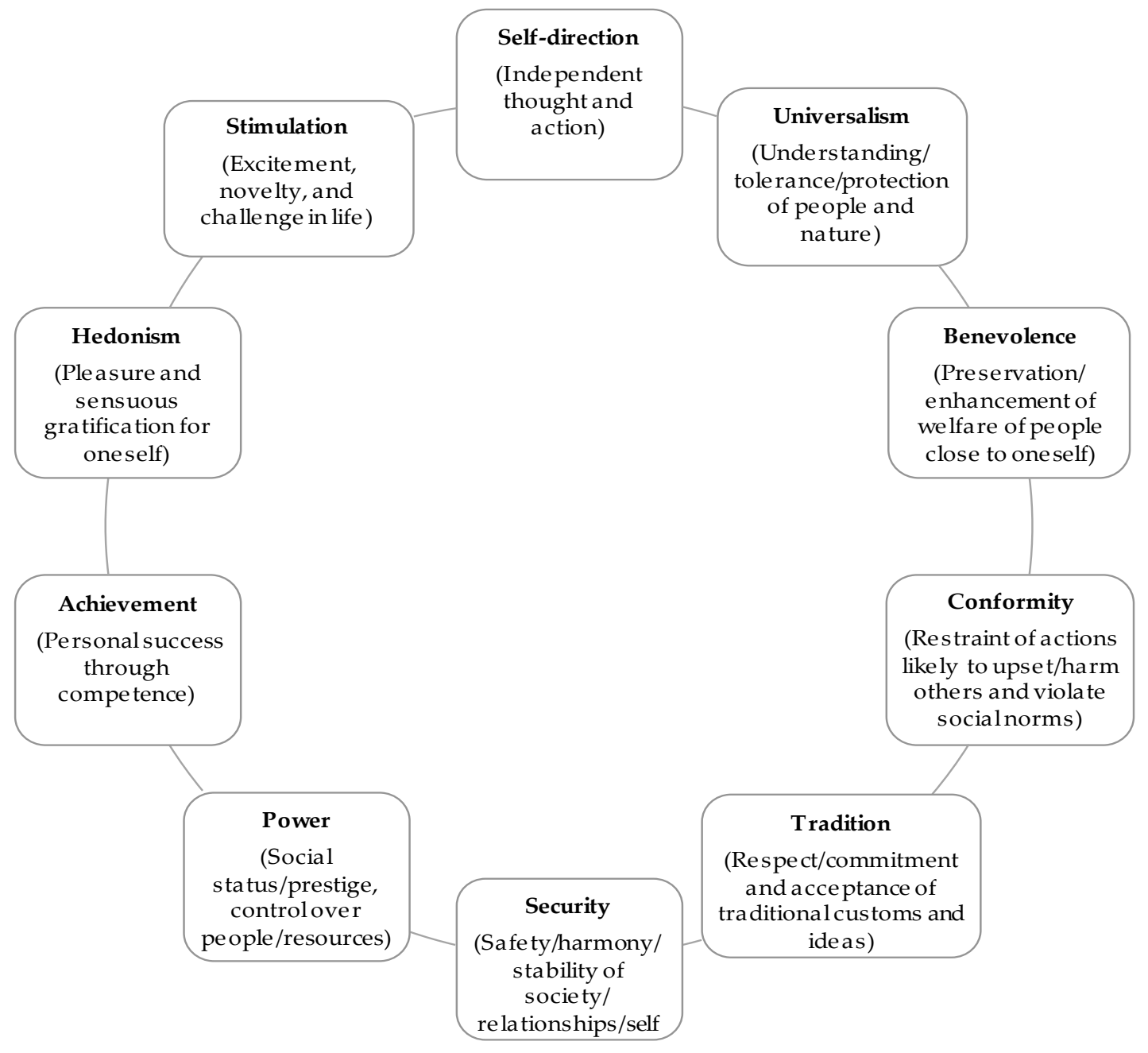

Besides its importance for "cognitive flexibility" and "adaptive orientation," it is here also suggested that human values are important for the value individuals place on resources. Morelli and Cunningham (2012) have argued that what they call "resource-importance appraisal" is a critical but often overlooked aspect of the COR theory for understanding the reactions and strategies of individuals to both actual and potential loss of resources. How threatening the loss of a particular resource is experienced by an individual should be influenced by how valuable this resource is perceived to be. This makes intuitive sense, not 
least in the context of job insecurity: it seems plausible that people who place a high value on stability and predictability in their lives will react more strongly to threats to the disruption of the employment relationship.

Thus, it is suggested here that human values may serve two important functions in the job insecurity - wellbeing/life satisfaction relationship. Firstly, since values contain a motivational component, they may act as a positive energy source to cope with a changing work environment. Values serve as standards or criteria against which events are evaluated, and employees who are motivated by "stimulation" values - excitement, novelty and challenges in life - are more likely to reinterpret the threat of job loss as a challenge and to focus on what they might gain, instead of what they stand to lose in the event of job insecurity. It could even be argued that job insecurity may even be a positive stressor for people who are strongly motivated by "motivation" values. Just as employment has a symbolic value in that it helps people to define for themselves and others who they are, the way people tackle job insecurity as a challenge, rather than a threat - may have symbolic value in that it helps to define for people who they are. Conversely, for individuals who are motivated by "security" values, the room for reinterpretation of job insecurity is much more limited. Secondly, human values influence the value placed on a stable employment relationship ("resource-importance appraisal"). Individuals who place a high value on safety, harmony and stability of society, of relationships, and of self will also perceive that they will lose more in the case of dismissal.

In fact, what we are proposing is that the value dimension "stimulation," primarily through its role in cognitive flexibility and adaptive orientation, and "security," primarily through its role in "resource-importance appraisal," will function as moderators in the relationship between job insecurity and wellbeing and life satisfaction. This is illustrated in Figure 2 (below).

Although we have argued here that the value dimension "stimulation" primarily has importance for cognitive flexibility and adaptive orientation, whereas the value dimension "security" mainly has importance for resource-importance appraisal, it is crucial to recognise that these value dimensions, to an important extent, are mirror images of each other. Thus, individuals or social groups that are emphasising "stimulation" values also tend, on average, to place less emphasis on "security" values (Schwartz, 2003).

The role of human values as moderating factors in the analysis of how job insecurity affects life satisfaction and wellbeing has, to our knowledge, not been considered before. The role of values for stress and wellbeing more generally has been the subject of a few studies, the most relevant for the present study being the one by Bouckenooghe, Buelens, Fontaine, and Vanderheyden (2005). Drawing upon theories about growth- and deficiency-related needs, they argue that "stimulation" and related values are growth-related and are likely to alleviate stress, whereas "security" and related values are deficiency-related and therefore should correlate in a positive way with stress. They also found substantial support for these hypotheses. Also of relevance here is research showing that psychological resources such as locus of control are positively related to general wellbeing ( $\mathrm{Ng}$, Sorensen, \& Eby, 2006). 
Figure 2. Theoretical Model

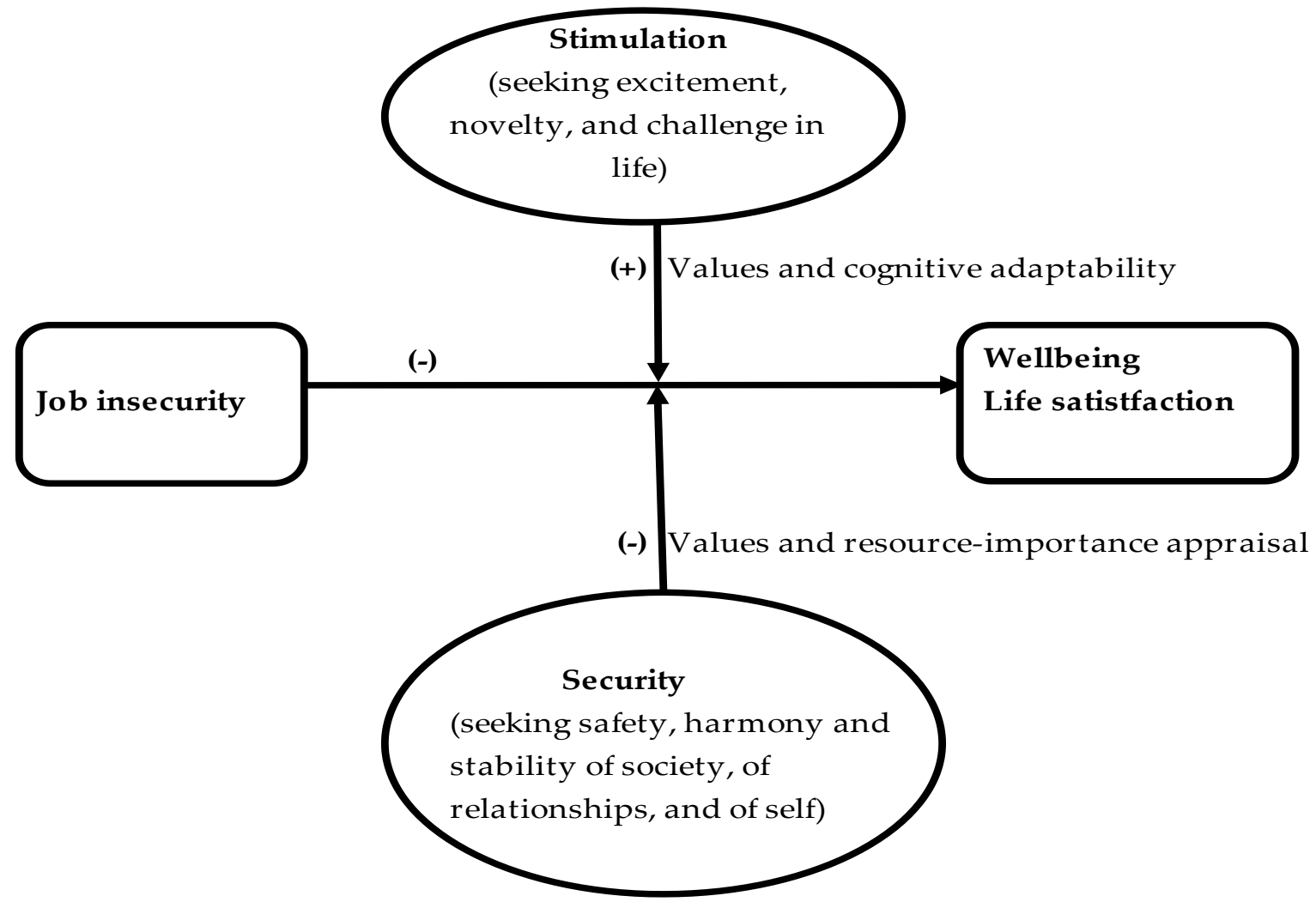

\section{Methods}

The data used in this study is the European Social Survey (ESS) from 2004 and 2010. The ESS data are suitable for addressing the research questions advanced in this study, since they contain information on human values, job insecurity, measures of subjective wellbeing and life satisfaction, and a rich set of background characteristics of participating respondents. Unfortunately, the data does not contain information on respondents' job satisfaction. The comparative nature of the data also makes it possible to take into account macro-level characteristics that have been shown to be of importance for job insecurity, subjective wellbeing and life satisfaction. The data used in this study are the result of representative population surveys using a standardised questionnaire carried out in 28 countries (AT, BE, BG, CY, CZ, DE, DK, EE, ES, FI, FR, GB, EL, HU, IE, IS, IT, LT, LU, NL, NO, PL, PT, SE, SK, SI, TR and TR). The average response rate is $61.2 \%$, ranging from $30.5 \%$ in Germany in 2010 to $78.8 \%$ in Greece in 2010. The dataset used is restricted to employed individuals aged between 25 and 60 years at the time of the survey. A weighting factor has been used in all analyses to correct for sample selection bias (European Social Survey, 2014).

Job insecurity is measured using the item: "Using this card, please tell me how true each of the following statements is about your current job: My job is secure," where possible answers are (1) "not at all true," (2) "a little true," (3) "quite true," and (4) "very true." Following other studies using this variable (see, e.g., Esser \& Olsen, 2012), this measure was dichotomised, and job insecurity is assumed to exist when respondents have answered "not at all true" or "a little true," resulting in $35.7 \%$ of the respondents defined as experiencing job insecurity. 
This study will use two different but related measures of subjective wellbeing: the WHO-3 scale and overall self-reported life satisfaction. The WHO-3 scale is designed to measure positive psychological wellbeing such as positive mood, vitality, and general interest (Bech, 2004), and is measured with the following three items:

"I am going to read out a list of statements about how you may have been feeling recently. For each statement, using this card, I would like you to say how often you have felt like this over the last two weeks: (i) 'I have felt cheerful and in good spirits,' (ii) 'I have felt calm and relaxed,' (iii) 'I have felt active and vigorous," where possible answers are (1) "at no time," (2) "some of the time," (3) "less than half of the time," (4) "more than half of the time," (5) "most of the time," and (6) "all of the time."

Cronbach's alpha across the whole sample is 0.82 . Life satisfaction was measured using the following question:

"All things considered, how satisfied are you with your life as a whole nowadays?" where the response scale varies between 0 "extremely dissatisfied" and 10 "extremely satisfied."

The measurement of human values in the ESS is based on the methodology of verbal portraits, where respondents are asked to compare themselves to portraits describing a person's goals, aspirations, or wishes that point implicitly to the importance of a single value (Schwartz, 2006b). The ESS human scale is derived from the 40-item Portrait Values Questionnaire (PVQ) where two portraits operationalise each value (Schwartz, 2003). The portraits forming the basis for the value dimensions "security" and "stimulation" that are the focus of this study are the following:

Now I will briefly describe some people. Please listen to each description and tell me how much each person is or is not like you.

\section{Security}

A. It is important to her/him to live in secure surroundings. She/he avoids anything that might endanger her/his safety.

B. It is important to her/him that the government ensures her/his safety against all threats. She/he wants the state to be strong so it can defend its citizens.

\section{Stimulation}

A. She/he likes surprises and is always looking for new things to do. She/he thinks it is important to do lots of different things in life.

B. She/he looks for adventures and likes to take risks. She/he wants to have an exciting life.

Possible answers are (1) "not like me at all" (2) "not like me" (3) "a little like me" (4) "somewhat like me" (5) "like me" (6) "very much like me." To assess value priorities and to correct for individual differences in the use of the response scale, each person's responses were centred on his or her own mean score on all 21 items forming the 10 value dimensions, which converts absolute value scores into scores that indicate the relative importance of each value to the person (Schwartz, 2003). 
Testing of the human value instruments in the ESS indicates that it is difficult to discriminate between the adjacent values: conformity and tradition, universalism and benevolence, and power and achievement (Davidov, Schmidt, \& Schwartz, 2008). Therefore, in the analyses where individual scores on other value dimensions are entered as control variables, these three pairs of values were combined, resulting in a total of seven value factors

The hypothesis that human values (VAL) may moderate the relationship between job insecurity (INSEC) and wellbeing and life satisfaction will be tested using the so-called simple linear moderation model (Hayes, 2013) (Equation 1).

$$
\begin{aligned}
& Y_{i j t}=\alpha+v_{j}+\beta_{1} I N S E C_{i j t}+\beta_{2} V A L_{i j t}+\beta_{3} I N S E C * V A L_{i j t}+\beta_{4} X_{i j t}+\beta_{5} Z_{j t}+ \\
& \mu_{i j t} \quad(1) \\
& \text { where } \mathrm{i}=1 \ldots \mathrm{n}, \mathrm{j}=1 \ldots 28 \text {, and } \mathrm{t}=2004,2010 .
\end{aligned}
$$

The regression coefficient $\beta_{3}$ captures the extent to which INSEC is conditional upon VAL. With the value dimension "security" in the model, we expect $\beta_{3}$ to be negative: the more individuals are motivated by avoiding uncertainty and the more they resist change, the more negative will be the impact of job insecurity on wellbeing and life satisfaction. With the value dimension "stimulation" in the model, we expect $\beta_{3}$ to be positive: the more individuals are motivated by a desire for taking on challenges in life and the more they seek variety, the more positive will be the impact of job insecurity on wellbeing and life satisfaction. All models also include vectors of control variables at the individual $\left(X_{i j t}\right)$ and country $\left(Z_{j t}\right)$ level, and an error term $\left(\mu_{i j t}\right)$. To the extent that subjective wellbeing and life satisfaction are related to unobserved differences between countries, the model also includes unit-fixed effects at the country level $\left(\alpha+v_{j}\right.$, with $v_{j}$ estimated by $\mathrm{N}-1$ country dummies) to account for this unobserved heterogeneity. All models also include a time fixed effect to allow for heterogeneity between the two survey waves.

Based on previous research, the following individual-level variables were included in all models to control for potential confounding: age, gender, education (years), household size, whether the respondent currently lives with a partner, form of work contract (limited or unlimited duration), working time, if the respondent lives with children, work demands, workrelated control and social support, career opportunities, work-related rewards and the social network of the respondents. Answer categories to these variables can be found in Table A1 (in Appendix A). Earlier research has indicated that a number of factors at the macro level also are of importance for assessing the incidence of subjective job insecurity and its relationship with subjective wellbeing (Erlinghagen, 2008; Sjöberg, 2010). All models therefore control for the social expenditure per capita (since access to sources of income during unemployment might influence the perceived economic consequences of losing one's job), unemployment levels (since high unemployment levels increase the threat of unemployment for all), and GDP per capita (in an attempt to control for country-level differences in living standards).

\section{Results}

Table 1 (below) reports the results from a series of regression models based on Equation 2. Only results for the variables of primary interest are reported, and results for the full set of individual- and country-level variables can be found in Table A1. 
Table 1. Results from fixed-effects OLS regressions with life satisfaction and subjective wellbeing a dependent variables. Unstandardised regression coefficients $w$ ith cluster-robust standard errors

Life satisfaction

(1)
(2)

(3)

Subjective wellbeing (WHO-3)

\begin{tabular}{|c|c|c|c|c|c|c|}
\hline Job insecurity & $\begin{array}{c}-0.239^{* * *} \\
(0.041)\end{array}$ & $\begin{array}{c}-0.193^{* * *} \\
(0.042)\end{array}$ & $\begin{array}{c}-0.199^{* * * *} \\
(0.042)\end{array}$ & $\begin{array}{c}-0.214^{* * *} \\
(0.055)\end{array}$ & $\begin{array}{c}-0.155^{* * *} \\
(0.051)\end{array}$ & $\begin{array}{c}-0.147^{* * *} \\
(0.054)\end{array}$ \\
\hline \multicolumn{7}{|l|}{ Value dimensions } \\
\hline Security & $\begin{array}{c}-0.053^{* * *} \\
(0.026)\end{array}$ & $\begin{array}{l}-0.010 \\
(0.023)\end{array}$ & $\begin{array}{c}-0.053^{* * *} \\
(0.018)\end{array}$ & $\begin{array}{c}-0.085^{* * *} \\
(0.036)\end{array}$ & $\begin{array}{l}-0.029 \\
(0.043)\end{array}$ & $\begin{array}{c}-0.085^{* *} \\
(0.036)\end{array}$ \\
\hline Stimulation & $\begin{array}{c}0.005 \\
(0.017)\end{array}$ & $\begin{array}{c}0.004 \\
(0.017)\end{array}$ & $\begin{array}{l}-0.017 \\
(0.018)\end{array}$ & $\begin{array}{c}0.172^{* * * *} \\
(0.025)\end{array}$ & $\begin{array}{c}0.171^{* * *} \\
(0.025)\end{array}$ & $\begin{array}{c}0.136^{* * *} \\
(0.030)\end{array}$ \\
\hline \multicolumn{7}{|c|}{ Interactions job insecurity - value dimensions } \\
\hline Job insecurity*Security & & $\begin{array}{c}-0.134^{* * *} \\
(0.041)\end{array}$ & & & $\begin{array}{c}-0.172^{* *} \\
(0.060)\end{array}$ & \\
\hline Job insecurity*Stimulation & & & $\begin{array}{c}0.064^{* *} \\
(0.027)\end{array}$ & & & $\begin{array}{c}0.107^{* *} \\
(0.046)\end{array}$ \\
\hline Constant & $\begin{array}{l}5.554^{* *} \\
(0.979)\end{array}$ & $\begin{array}{l}5.524^{* *} \\
(0.973)\end{array}$ & $\begin{array}{l}5.529^{* *} \\
(0.984)\end{array}$ & $\begin{array}{c}9.757^{* * *} \\
(1.144)\end{array}$ & $\begin{array}{c}9.718^{* * *} \\
(1.136)\end{array}$ & $\begin{array}{c}9.716^{* * *} \\
(1.143)\end{array}$ \\
\hline Observations & 24828 & 24828 & 24828 & 24831 & 24831 & 24831 \\
\hline R-squared & 0.292 & 0.293 & 0.292 & 0.124 & 0.125 & 0.124 \\
\hline
\end{tabular}

${ }^{* * *} \mathrm{p}<0.01 ;{ }^{* *} \mathrm{p}<0.05 ;{ }^{*} \mathrm{p}<0.1$

Throughout the different model specifications, the coefficient associated with job insecurity is negative and significant at the $1 \%$ level, indicating that job insecurity in itself is associated with lower levels of life satisfaction and subjective wellbeing. Model 1, with life satisfaction as the dependent variable, indicates that the value dimension "security" is negatively correlated with life satisfaction $(\beta=-0.053, \mathrm{p}<0.01)$, whereas there is no significant relationship between the value dimension "stimulation" and life satisfaction. Excluding either one of these value dimensions from the model has no significant effect on the results. The coefficient associated with the interaction effect between job insecurity and the value dimension "security" (model 2) is negative $(\beta=-0.134, \mathrm{p}<0.01)$, indicating that the more individuals in an insecure employment emphasise "security" values, the lower is their life satisfaction. Model 3 indicates that also the value dimension "stimulation" is moderating the relationship between job insecurity and life satisfaction, but in the opposite direction as compared to the value dimension "security": the coefficient associated with the interaction between job insecurity and the value dimension 
"stimulation" is positive $(\beta=0.064, \mathrm{p}<0.05)$. Thus, individuals who score high on the "stimulation" value dimension tend to report higher levels of life satisfaction when faced with job insecurity.

Models with subjective wellbeing (WHO-3) as the dependent variable provide further support for the notion that "security" and "stimulation" values moderate the relationship between job insecurity and subjective wellbeing, but in opposite directions. According to model 5 , individuals who emphasise "security" values also tend to report lower levels of subjective wellbeing when faced with job insecurity $(\beta=-0.172, \mathrm{p}<0.05)$, whereas individuals who emphasise "stimulation" values tend to report higher levels of subjective wellbeing in a situation when they evaluate their employment relationship as being insecure $(\beta=0.107$, $\mathrm{p}<0.05)$.

A number of sensitivity tests support the results from the models in Table 1. To check for possible outliers, models 2, 3, 5 and 6 were re-estimated using a jack-knife procedure omitting first one country, then every possible combination of two countries. Throughout these sensitivity tests, the coefficients associated with the interaction between job insecurity and the value dimension "security" with life satisfaction as the dependent variable (model 2) are negative, with over $97 \%$ of the coefficients being significant at the $1 \%$ level and the remaining being significant at the $5 \%$ level. The smallest coefficient (absolute value) is -0.102 (when Lithuania is excluded, together with either Poland, Portugal or Slovenia) and the largest coefficient is -0.170 (when the Czech Republic and Germany are excluded). The same interactions with WHO-3 as the dependent variable (model 5) are also rather insensitive to the exclusion of countries: when one or any combination of two countries is excluded, all coefficients are significant on at least the $5 \%$ level, and $40 \%$ of the coefficients are significant at the $1 \%$ level. The smallest coefficient (absolute value) is -0.127 (when the Czech Republic and Slovakia are excluded), and the largest coefficient is -0.218 (when Greece is excluded). Furthermore, all coefficients associated with the interaction between job insecurity and value dimension "stimulation" with life satisfaction as the dependent variable (model 3) are positive and significant on at least the $10 \%$ level, and $81 \%$ of the coefficients are significant at the $1 \%$ or $5 \%$ level. The largest coefficient is 0.081 (when Ireland and Poland are excluded), and the smallest coefficient is 0.038 (when Lithuania and Slovakia are excluded). However, sensitivity tests for the same interactions with WHO-3 as the dependent variable (model 6) show that five coefficients are not significant (when the Czech Republic is excluded, together with Switzerland, Denmark, France, Great Britain or Slovakia). However, all these coefficients have a p-value below 0.12 and are thus close to being significant at the $10 \%$ level. The same sensitivity tests also indicate that six of the coefficients are significant at the $1 \%$ level (when Belgium is excluded, together with the Czech Republic, Lithuania, the Netherlands, Poland, and Turkey, and when Lithuania is excluded, together with Portugal).

Sensitivity tests also indicate that including other value dimensions in the models has very little impact on the regression coefficients of interest. When any combination of up to four of the other value dimensions (i.e., self-direction, hedonism and the combined value dimensions conformity and tradition, universalism and benevolence, and power and achievement) are included in the models, no coefficient size associated with the interaction variables is differing by more than $8 \%$ and all coefficients are within the significance levels reported in Table 1 . Finally, the models in Table 1 can also be estimated using hierarchical (or multilevel) linear regression models with random (instead of fixed) effects at the country level. Such models show very similar results to the models presented in Table 1, with no coefficient size associated 
with the interaction variables differing by more than $2 \%$ and all coefficients being within the significance levels reported in Table 1.

In a simple linear-additive regression, the effect of a variable $x$ on the dependent variable $y$ is simply its coefficient, $\beta x$. However, the interaction terms of interactive models have multiple effects, and to assess properly the full effect of such interaction terms, we must consider simultaneously how they affect the coefficients of the single variables that comprise the interaction terms, as well as how the coefficient of the interaction term depends on the other values of the other variables with which it interacts. Figures 3a-d (below) therefore present predicted values (together with 95\% confidence intervals) from models 2, 3, 5, and 6 from Table 1 , where the value dimensions "security" and "stimulation" have been standardised to vary between 0 and 1 .

Figures $3 a$ and $3 c$ illustrate that for individuals who evaluate their employment relationship as being secure, predicted levels of life satisfaction and subjective wellbeing (WHO-3) are rather insensitive to how these individuals score on the value dimension "security" (dotted lines). However, for individuals experiencing job insecurity, their levels of life satisfaction and wellbeing become significantly lower the more they emphasise "security" values (solid lines). Individuals in an insecure employment relationship who place a low value on "security" values actually have predicted higher levels of life satisfaction and subjective wellbeing than individuals who do not experience job insecurity, although this difference is not significant.

The importance of human values as moderating factors is perhaps even more striking for the value dimension "stimulation." Figure $3 \mathrm{~b}$ shows that predicted levels of life satisfaction are rather insensitive to how individuals in a secure employment relationship score on the value dimension "stimulation" (dotted line). Individuals who evaluate their employment relationship as being insecure (solid line), however, experience higher predicted levels of life satisfaction the more they emphasise "stimulation" values, up to a point where there is no significant difference in predicted levels of life satisfaction between this group and individuals who evaluate their employment relationship as being secure. Figure $3 \mathrm{~d}$ shows that predicted levels of subjective wellbeing (WHO-3) increase markedly for individuals in a secure employment relationship the more individuals in this group emphasise stimulation values. But since the subjective wellbeing of individuals in an insecure employment relationship increases even more strongly, the wellbeing of individuals in secure and insecure employment relationships, respectively, is converging and is at roughly the same (predicted) level as high scores on the "stimulation" value dimension.

What, then, is the societal relevance of these effects? In Figure 3a (corresponding to model 2 ), around $12 \%$ of individuals experiencing job insecurity score so low on the "security" value dimension that their life satisfaction is not significantly worse (at the $5 \%$ level) than individuals in a secure employment relationship. The corresponding figure for subjective wellbeing (WHO3 , Figure $3 c$ ) is $22 \%$. In Figure $3 b$, around $6 \%$ of individuals who experience job insecurity score so high on the "stimulation" value dimension that there is no significant difference in life satisfaction between this group and individuals in a secure employment relationship. The corresponding figure for subjective wellbeing (WHO-3, Figure $3 \mathrm{~d}$ ) is around $23 \%$. 


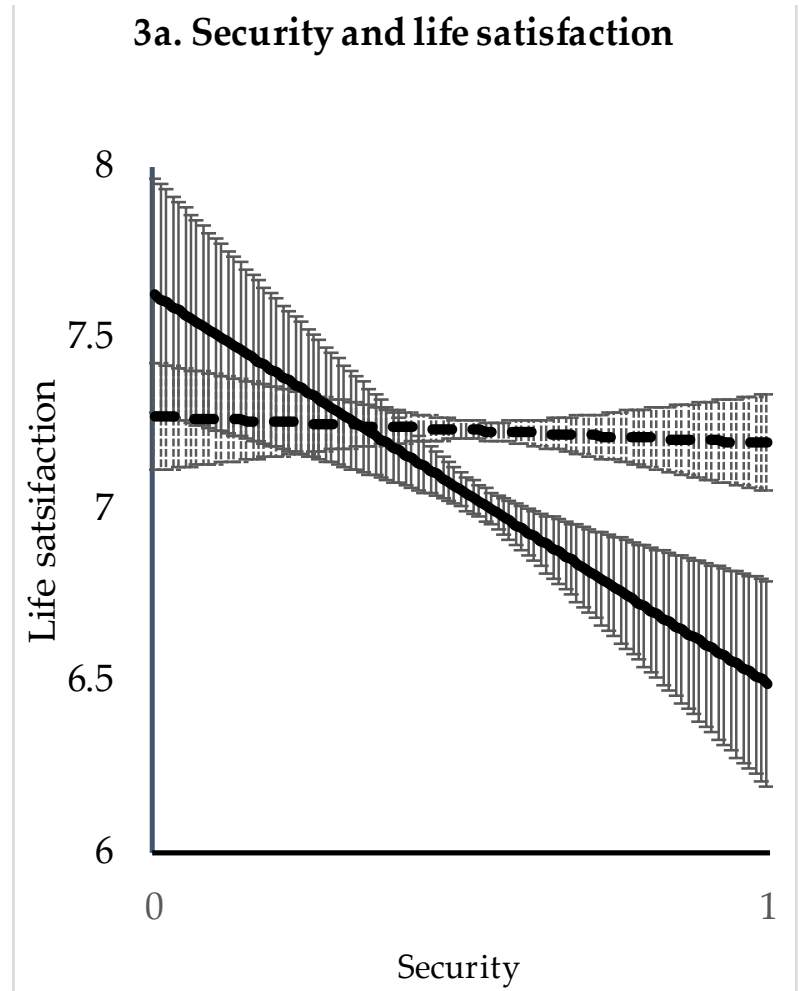

-- -Secure Insecure

3c. Security and WHO-3

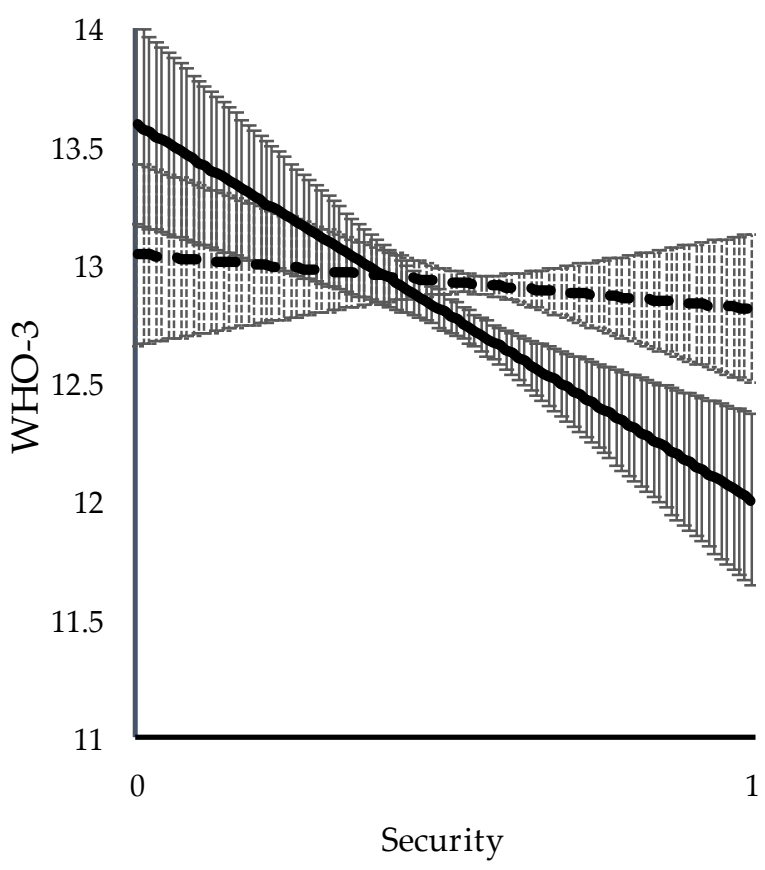

- - Secure Insecure 3b. Stimulation and life satisfaction

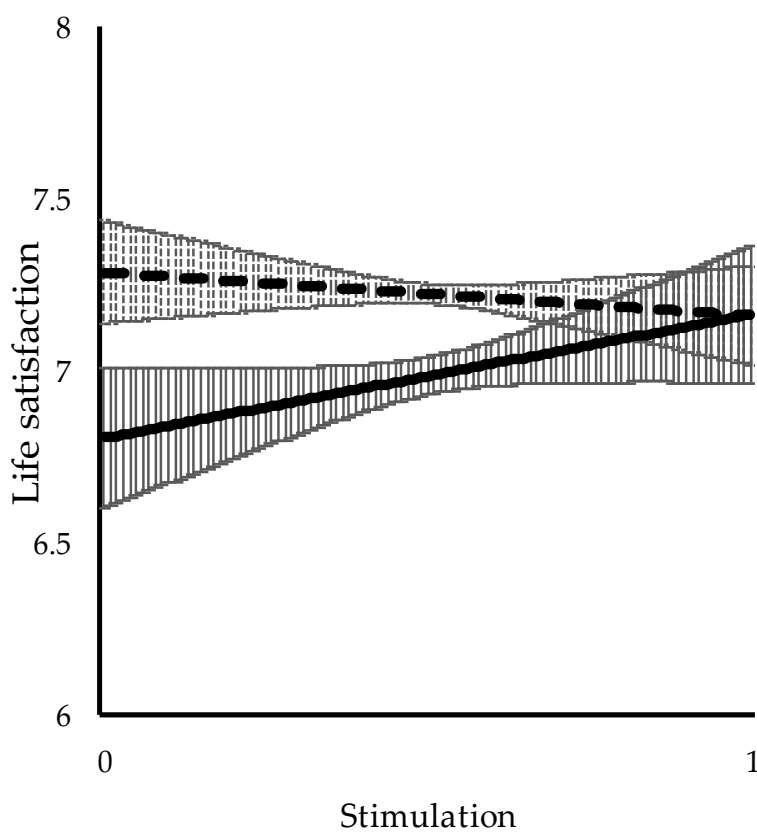

- - - Secure Insecure

3d. Stimulation and WHO-3

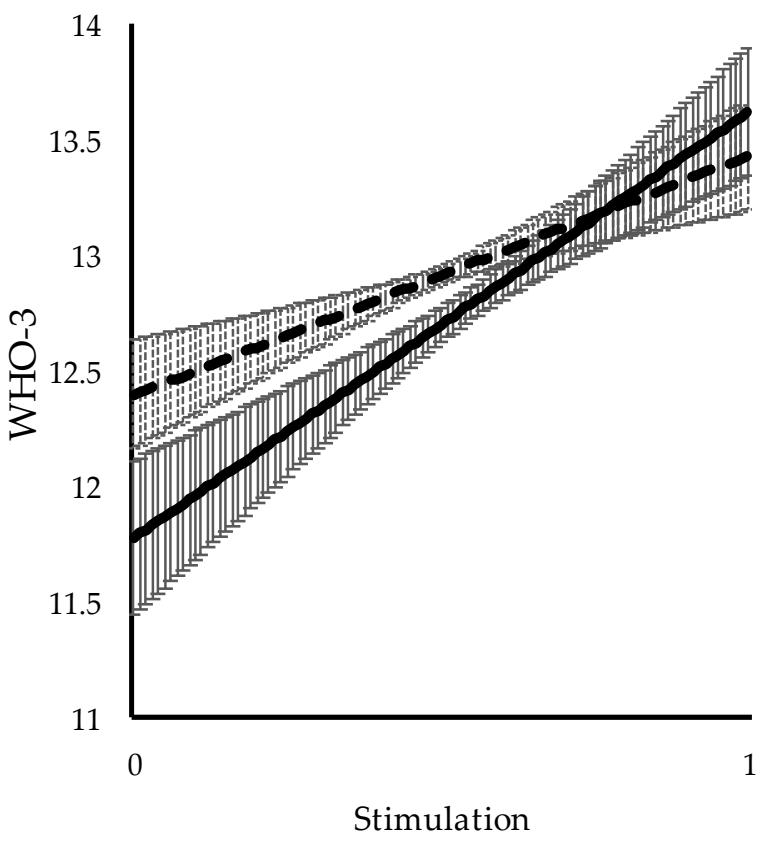

--•Secure Insecure 


\section{Discussion and conclusion}

The theoretical framework presented here has provided important new insights into the relationship between job insecurity, life satisfaction and subjective wellbeing. The empirical analyses confirm the conclusion from previous research that job insecurity is negatively related to both life satisfaction and subjective wellbeing. However, these analyses also demonstrate that the extent to which job insecurity is related to life satisfaction and subjective wellbeing is conditional upon individual value orientations. The more individuals experiencing job insecurity hold "security" values and the more they are motivated to avoid uncertainty and resist change, the stronger is the negative effect of job insecurity on their life satisfaction and subjective wellbeing. This is hardly surprising. A more intriguing conclusion is that the more people hold "stimulation" values and the more they are motivated by a desire to take on challenges in life and to seek variety, the smaller is the effect of job insecurity on life satisfaction and subjective wellbeing, up to a point where there is no difference in these two outcomes between people who experience job insecurity and those who do not. Between $6 \%$ and $23 \%$ of individuals experiencing job insecurity score so high on the "stimulation" value dimension, alternatively score so low on the "security" value dimension, that there is no significant difference in life satisfaction or subjective wellbeing between this group and individuals who are not experiencing job insecurity.

One obvious limitation of the research design in this study is that data is cross-sectional, which makes it difficult to discern cause-effect relationships (De Witte et al., 2016). Another potential limitation is related to what in the literature has been known as the "reinforcement hypothesis," which basically argues that rewards obtained on the job grow in importance over time, whereas the absence of particular job rewards lessens their value over time. The implication of this hypothesis for the current study is that the presence of job insecurity over time would lessen "security" values and reinforce "stimulation" values. If "stimulation" in itself is associated with higher life satisfaction and subjective wellbeing, this could bias the results presented here. However, as argued by Rokeach (1968), a minimal level of value stability is necessary for the continuity of personality. This implies that values are relatively stable over time, which would reduce potential bias caused by such reinforcement effects.

An important question for future research is how human values relate to psychological resources such as locus of control, self-esteem, and optimism. In this study, we have consistently used the term "psychological resources," as we adhere to the view that such resources are more states than traits and therefore they are also amenable to change over time. Theoretically, there are reasons to believe that human values are a more fundamental characteristic of people than many psychological resources. However, this has yet to be empirically tested, as has the question of whether human values, as defined in this study, may be seen as a fundamental source of such psychological resources.

\section{Author}

Ola Sjöberg

Stockholm University

Ola.Sjoberg@sofi.su.se 


\section{Publishing Timeline}

Received 23 May 2017

Accepted 1 May 2018

Published 13 July 2018

\section{References}

Bech, P. (2004). Measuring the dimension of psychological general well-being by the WHO-5. Quality of Life Newsletter, 32, 15-16.

Bouckenooghe, D., Buelens, M., Fontaine, J., \& Vanderheyden, K. (2005). The prediction of stress by values and value conflict. The Journal of Psychology, 139(4), 369-384. https://dx.doi.org/10.3200/JRLP.139.4.369-384

Davidov, E., Schmidt, P., \& Schwartz, S. H. (2008). Bringing values back in: The adequacy of the European Social Survey to measure values in 20 countries. Public Opinion Quarterly, 72(3), 420-445. https://doi.org/10.1093/poq/nfn035

De Cuyper, N., Mäkikangas, A., Kinnunen, U., Mauno, S., \& Witte, H. D. (2012). Cross-lagged associations between perceived external employability, job insecurity, and exhaustion: Testing gain and loss spirals according to the conservation of resources theory. Journal of Organizational Behavior, 33(6), 770-788. https://dx.doi.org/10.1002/job.1800

De Witte, H. (1999). Job insecurity and psychological well-being: Review of the literature and exploration of some unresolved issues. European Journal of Work and Organizational Psychology, 8(2), 155-177. http://dx.doi.org/10.1080/135943299398302

De Witte, H. (2005). Job insecurity: Review of the international literature on definitions, prevalence, antecedents and consequences. SA Journal of Industrial Psychology, 31(4), 1-6. https://doi.org/10.4102/sajip.v31i4.200

De Witte, H., Pienaar, J., \& De Cuyper, N. (2016). Review of 30 years of longitudinal studies on the association between job insecurity and health and well-being: Is there causal evidence? Australian Psychologist, 51(1), 18-31. https://dx.doi.org/10.1111/ap.12176

Erlinghagen, M. (2008). Self-perceived job insecurity and social context: A multi-level analysis of 17 European countries. European Sociological Review, 24(2), 183-197. https://doi.org/10.1093/esr/jcm042

Esser, I., \& Olsen, K. M. (2012). Perceived job quality: Autonomy and job security within a multi-level framework. European Sociological Review, 28(4), 443-454. https://doi.org/10.1093/esr/jcr009

European Social Survey. (2014). Weighting European social survey data. https://www.europeansocialsurvey.org/docs/methodology/ESS weighting data 1.pdf

Ferrie, J. E., Westerlund, H., Virtanen, M., Vahtera, J., \& Kivimäki, M. (2008). Flexible labor markets and employee health. Scandinavian Journal of Work, Environment \& Health Supplements, 6, 98-110.

Fletcher, D. \& Sarkar, M. (2013). Psychological resilience. European Psychologist, 18(1), 12-23. https://dx.doi.org/10.1027/1016-9040/a000124

Good, D. (2014). Predicting real-time adaptive performance in a dynamic decision-making context. Journal of Management \& Organization, 20(6), 715-732. https://dx.doi.org/10.1017/jmo.2014.54

Griep, Y., Kinnunen, U., Nätti, J., De Cuyper, N., Mauno, S., Mäkikangas, A., \& De Witte, H. (2016). The effects of unemployment and perceived job insecurity: A comparison of their association with psychological and somatic complaints, self-rated health and life satisfaction. International Archives of Occupational and Environmental Health, 89(1), 147-162. https://doi.org/10.1007/s00420-015-1059-5

Hayes, A. (2013). Introduction to mediation, moderation, and conditional process analysis: A regression-based approach. New York, NY: Guilford Press.

Hobfoll, S. E. (1989). Conservation of resources: A new attempt at conceptualizing stress. American Psychologist, 44(3), 513-524. https://dx.doi.org/10.1037/0003-066X.44.3.513

Hobfoll, S. E. (2001). The influence of culture, community, and the nested-self in the stress process: Advancing conservation of resources theory. Applied Psychology, 50(3), 337-421.

https://dx.doi.org/10.1111/1464-0597.00062 
Ito, J. K \& Brotheridge, C. M. (2007). Exploring the predictors and consequences of job insecurity's components. Journal of Managerial Psychology, 22(1), 40-64. https://dx.doi.org/10.1108/02683940710721938

Jahoda, M. (1982). Employment and unemployment: A social-psychological analysis. Cambridge, England: Cambridge University Press.

Kobasa, S. C., Maddi, S. R., \& Courington, S. (1981). Personality and constitution as mediators in the stress-illness relationship. Journal of Health and Social Behaviour, 22(4), 368378. https://doi.org/10.2307/2136678

König, C. J., Debus, M. E., Häusler, S., Lendenmann, N., \& Kleinmann, M. (2010). Examining occupational self-efficacy, work locus of control and communication as moderators of the job insecurity-job performance relationship. Economic and Industrial Democracy, 31(2), 231-247. https://dx.doi.org/10.1177/0143831X09358629

Mauno, S., Kinnunen, U., \& Ruokolainen, M. (2007). Job demands and resources as antecedents of work engagement: A longitudinal study. Journal of Vocational Behavior, 70(1), 149-171. https://doi.org/10.1016/j.jvb.2006.09.002

Mäkikangas, A. \& Kinnunen, U. (2003). Psychosocial work stressors and well-being: Self-esteem and optimism as moderators in a one-year longitudinal sample. Personality and Individual Differences, 35(3), 537-557. https://doi.org/10.1016/S0191-8869(02)00217-9

Morelli, N. A., \& Cunningham, C. J. L. (2012). Not all resources are created equal: COR theory, values, and stress. The Journal of Psychology, 146(4), 393-415. https://dx.doi.org/10.1080/00223980.2011.650734

Ng, T. W. H., Sorensen, K. L., \& Eby, L. T. (2006). Locus of control at work: A meta-analysis. Journal of Organizational Behavior, 27(8), 1057-1087. https://dx.doi.org/10.1002/job.416

Richardson, G. E. (2002). The metatheory of resilience and resiliency. Journal of Clinical Psychology, 58(3), 307-321. https://dx.doi.org/10.1002/jclp.10020

Rokeach, M. (1968). The role of values in public opinion research. Public Opinion Quarterly, 32(4), 547-559. https://doi.org/10.1086/267645

Schwartz, S. H. (2003). A proposal for measuring value orientations across nations. In Questionnaire development report of the European Social Survey (chap. 7).

https://www.europeansocialsurvey.org/docs/methodology/core ess questionnaire/ESS core questio nnaire human values.pdf

Schwartz, S. H. (2006a). A theory of cultural value orientations: Explication and applications. Comparative Sociology, 5(2), 137-182. https://doi.org/10.1163/1569133067786667357

Schwartz, S. H. (2006b). Value orientations: Measurement, antecedents and consequences across nations. In R. Jowell, C. Roberts, R. Fitzgerald, \& G. Eva. (Eds.). Measuring attitudes cross-nationally: Lessons from the European Social Survey (pp. 169-204). London, England: Sage.

Schwartz, S. H. (2015). Basic individual values: Sources and consequences. In D. Sander \& T. Brosch. (Eds.). Handbook of Value (pp. 63-84). Oxford, England: Oxford University Press.

Schwartz, S. H., Cieciuch, J., Vecchione, M., Davidov, E., Fischer, R., Beierlein, C., . . Konty, M. (2012). Refining the theory of basic individual values. Journal of Personality and Social Psychology, 103(4), 663688. https://dx.doi.org/10.1037/a0029393

Scott, H. K. (2004). Reconceptualizing the nature and health consequences of work-related insecurity for the new economy: The decline of workers' power in the flexibility regime. International Journal of Health Services, 34(1), 143-153. https://doi.org/10.2190/WAM3-MNN2-6UNF-FDEX

Silla, I., De Cuyper, N., Gracia, F. J., Peiró, J. M., \& De Witte, H. (2009). Job insecurity and well-being: Moderation by employability. Journal of Happiness Studies, 10(6), 739-751. https://doi.org/10.1007/s10902-008-9119-0

Sjöberg, O. (2010). Social insurance as a collective resource: Unemployment benefits, job insecurity and subjective well-being in a comparative perspective. Social Forces, 88(3), 1281-1304.

https://doi.org/10.1353/sof.0.0293

Van Dam, K. (2013). Employee adaptability to change at work: A multidimensional, resource-based framework. In S. Oreg, A. Michel, \& R. T. By (Eds.). The psychology of change: Viewing change from the employee's perspective (pp. 123-142). Cambridge, England: Cambridge University Press. 


\section{Appendix A}

Table A1. Unstandardised regression coefficients for micro- and macro variables from Table 1. Smallest/largest coefficients from models 1-6 (country fixed effects not shown).

\begin{tabular}{|c|c|c|}
\hline & $\begin{array}{l}\text { Life satisfaction } \\
\text { (models } 1-3 \text { ) }\end{array}$ & $\begin{array}{l}\text { Wellbeing } \\
\text { (models 4-6) }\end{array}$ \\
\hline Female (ref=male) & $0.062^{* *} / 0.064^{* *}$ & $-0.273^{* * *} /-0.271^{* * *}$ \\
\hline Age & $-0.012^{* * *} /-0.012^{* * *}$ & $-0.004 /-0.004$ \\
\hline Household size & $0.042^{* * *} / 0.043^{* * *}$ & $0.061^{* *} / 0.061^{* *}$ \\
\hline Lives with partner (ref=no) & $0.423^{* * *} / 0.423^{* * *}$ & $0.173^{* * *} / 0.173^{* * *}$ \\
\hline Children living at home (ref=no) & $-0.007 / 0.007$ & $-0.142^{* * *} /-0.142^{* * *}$ \\
\hline Years of full-time education & $0.001 / 0.001$ & $0.040^{* * *} / 0.040^{* * *}$ \\
\hline Working 21-36 hours/week (ref=1-20 hours/week) & $-0.079 /-0.079$ & $-0.083 /-0.082$ \\
\hline Working $>37$ hours/week (ref=1-20 hours/week) & $-0.057 /-0.054$ & $-0.004 /-0.003$ \\
\hline Limited contract (ref=unlimited contract) & $-0.067^{*} /-0.066^{*}$ & $0.048 / 0.049$ \\
\hline No contract (ref=unlimited contract) & $0.024 / 0.026$ & $-0.356^{* *} / 0.354^{* *}$ \\
\hline Years in full- or part-time work & $0.003 / 0.003$ & $0.009^{* *} / 0.009^{* *}$ \\
\hline Feelings about household income ${ }^{1}$ & $0.661^{* * *} / 0.662^{* * *}$ & $0.540^{* * *} / 0.541^{* * *}$ \\
\hline Job requires work very hard ${ }^{2}$ & $0.007 / 0.008$ & $-0.028 /-0.026$ \\
\hline Never enough time to get job done ${ }^{2}$ & $0.074^{* * *} / 0.075^{* * *}$ & $0.250^{* * *} / 0.251^{* * *}$ \\
\hline Health/safety at risk because of work ${ }^{3}$ & $-0.134^{* * *} /-0.133^{* * *}$ & $-0.198^{* * *} /-0.197^{* * *}$ \\
\hline There is a lot of variety in work ${ }^{3}$ & $0.148^{* * *} / 0.148^{* * *}$ & $0.182^{* * *} / 0.183^{* * *}$ \\
\hline Can decide start/finish work ${ }^{3}$ & $-0.015 /-0.015$ & $-0.062^{* * *} /-0.061^{* * *}$ \\
\hline Allowed to influence policy decisions ${ }^{4}$ & $0.016^{* *} / 0.016^{* *}$ & $0.018 / 0.018$ \\
\hline Can get support from co-workers ${ }^{3}$ & $0.166^{* * *} / 0.166^{* * *}$ & $0.273^{* * *} / 0.274^{* * *}$ \\
\hline My opportunities for advancement are good ${ }^{2}$ & $-0.092^{* * *} /-0.092^{* * *}$ & $-0.244^{* * *} /-0.243^{* * *}$ \\
\hline Wage depends on effort put into work ${ }^{3}$ & $-0.011 /-0.010$ & $0.041^{*} / 0.042^{*}$ \\
\hline How often meet socially with friends etc. ${ }^{5}$ & $0.245^{* * *} / 0.245^{* * *}$ & $0.444^{* * *} / 0.445^{* * *}$ \\
\hline Anyone to discuss personal matters with ${ }^{6}$ & $0.536^{* * *} / 0.536^{* * *}$ & $0.752^{* * *} / 0.753^{* * *}$ \\
\hline ESS wave 2010 (ref=2004) & $0.412^{* *} / 0.414^{* *}$ & $0.424^{*} / 0.426^{* * *}$ \\
\hline Unemployment $^{7}$ & $-0.016 /-0.016$ & $0.014 / 0.015$ \\
\hline GDP/capita $\left({ }^{*} 1000\right)^{8}$ & $0.023 / 0.024$ & $-0.036 /-0.036$ \\
\hline Social expenditure/inhabitant $\left({ }^{*} 1000\right)^{9}$ & $-0.325^{*} /-0.325^{*}$ & $0.073 / 0.074$ \\
\hline \multicolumn{3}{|c|}{${ }^{1}$ Answer categories range from $1=$ Very difficult on present income to $4=$ Living comfortably on present income } \\
\hline \multicolumn{3}{|c|}{${ }^{2} 1=$ agree strongly, $2=$ agree, $3=$ neither agree or disagree, $4=$ disagree, $5=$ disagree strongly } \\
\hline \multicolumn{3}{|c|}{${ }^{3} 1=$ not at all true, $2=$ a little true, $3=$ quite true, $4=$ very true } \\
\hline \multicolumn{3}{|c|}{${ }^{4}$ Answer categories range from $1=$ no influence to $10=$ complete control } \\
\hline \multicolumn{3}{|c|}{${ }^{5} 0=$ never - several times a month, $1=$ once a week - every day } \\
\hline \multicolumn{3}{|c|}{${ }^{6} 0=$ no, $1=$ yes } \\
\hline \multicolumn{3}{|c|}{${ }^{7}$ Unemployment, total (\% of total labour force): Source: World Bank, World Development Indicators. } \\
\hline \multicolumn{3}{|c|}{${ }^{8}$ GDP per capita, PPP (current international dollar). Source: World Bank, World Development Indicators. } \\
\hline \multicolumn{3}{|c|}{${ }^{9}$ Social protection benefits, purchansing power standard/inhibitant. Source: Eurostat Database. } \\
\hline
\end{tabular}

